\title{
Moving Granular-Bed Filter Development Program Option 1 - Component Test Facilities - Test Plan
}

\author{
Topical Report \\ September 8, 1995
}

RECEIVED

AllG 141997

O.S.TI

Work Performed Under Contract No.: DE-AC21-91MC27259

For

U.S. Department of Energy

Office of Fossil Energy

Morgantown Energy Technology Center

P.O. Box 880

Morgantown, West Virginia 26507-0880

By

Westinghouse Electric Corporation

Science and Technology Center

1310 Beulah Road

Pittsburgh, Pennsylvania 15235-5098

DISTAHEUTION OF THIS DOCUMENT IS UMIHITEA<smiles>CC=CC</smiles>
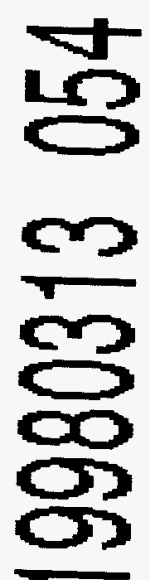


\section{Disclaimer}

This report was prepared as an account of work sponsored by an agency of the United States Government. Neither the United States Government nor any agency thereof, nor any of their employees, makes any warranty, express or implied, or assumes any legal liability or responsibility for the accuracy, completeness, or usefulness of any information, apparatus, product, or process disclosed, or represents that its use would not infringe privately owned rights. Reference herein to any specific commercial product, process, or service by trade name, trademark, manufacturer, or otherwise does not necessarily constitute or imply its endorsement, recommendation, or favoring by the United States Government or any agency thereof. The views and opinions of authors expressed herein do not necessarily state or reflect those of the United States Government or any agency thereof. 


\section{DISCLAIMER}

This report was prepared as an account of work sponsored by the United States Government. Neither the United States nor the United States Department of Energy, nor any of their employees, makes any warranty, express or implied, or assumes any legal liability or responsibility for the accuracy, completeness, or usefulness of any information, apparatus, product, or process disclosed, or represents that its use would not infringe privately owned rights. Reference herein to any specific commercial product, process, or service by trade name, mark, manufacturer, or otherwise, does not necessarily constitute or imply its endorsement, recommendation, or favoring by the United States Government or any agency thereof. The views and opinions of authors expressed herein do not necessarily state or reflect those of the United States Government or any agency thereof.

\section{PATENT STATUS}

This technical report is being transmitted in advance of DOE patent clearance and no further dissemination or publication shall be made of the report without prior approval of the DOE Patent Counsel.

\section{TECHNICAL STATUS}

This technical report is being transmitted in advance of DOE review and no further dissemination or publication shall be made of the report without prior approval of the DOE Project/Program Manager. 


\section{CONTENTS}

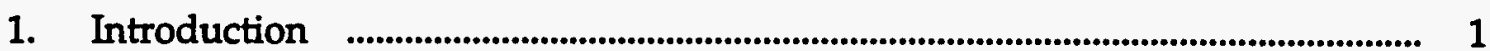

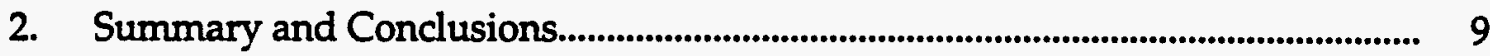

3. Option 1 Approach

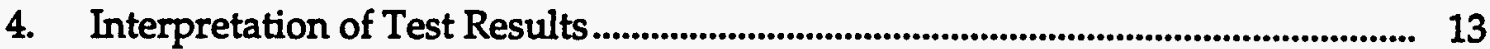

5. Design of Component Test Facilities................................................................. 14

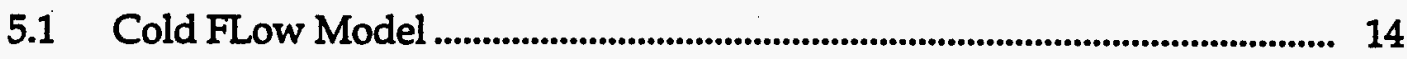

5.2 HTHP Test Facility........................................................................................ 22

6. Description of Engineering Modeling and

7. Description of Cold Flow Model Testing.............................................................. 27

8. Description of HTHP Performance Testing............................................................ 32

9. Estimated Cost and Schedule for Option 1 Test Program.................................... 35 


\section{INTRODUCTION}

Advanced, coal-based, power plants, such as IGCC and Advanced-PFBC, are currently nearing commercial demonstration. These power plant technologies require hot gas filtration as part of their gas cleaning trains. Ceramic barrier filters are the major filter candidates being developed for these hot gas cleaning applications. While ceramic barrier filters achieve high levels of particle removal, there are concerns for their reliability and operability in these applications.

An alternative hot gas filtration technology is the moving granular bed filter. These systems are at a lower state of development than ceramic barrier filters, and the current, moving granular-bed filter technologies are relatively large, complex, and costly systems in terms of their capital investment, their operating and maintenance cost, and their impact on the power plant efficiency. In addition, their effectiveness as filters is still in question. Their apparent attributes, relative to ceramic barrier filter systems, result from their much less severe mechanical design and materials constraints, and the potential for more reliable, failure-free particle removal operation.

The Westinghouse Science \& Technology Center has proposed a novel moving granular-bed filter concept, the Standleg Moving Granular-Bed Filter (SMGBF) system, that may overcome the inherent deficiencies of the current state-of-the-art moving granular-bed filter technology. The SMGBF is a compact unit that uses cocurrent gaspellet contacting in an arrangement that greatly simplifies and enhances the distribution of dirty, process gas to the moving bed and allows effective disengagement of clean gas from the moving bed.

The SMGBF vessel concept is elucidated in Figure 1. Dirty process gas is introduced into the top chamber of the filter vessel through a tangential entry. The moving bed media is introduced into the same chamber through a single, vertical dipleg pipe, where it spills from the base of the dipleg pipe to form a free surface having the normal media angle of repose. The dirty process gas enters the moving bed media through this free surface. Cocurrent flow of gas and bed media through the short, vertical standleg promotes intimate contact between the flowing gas stream and the 


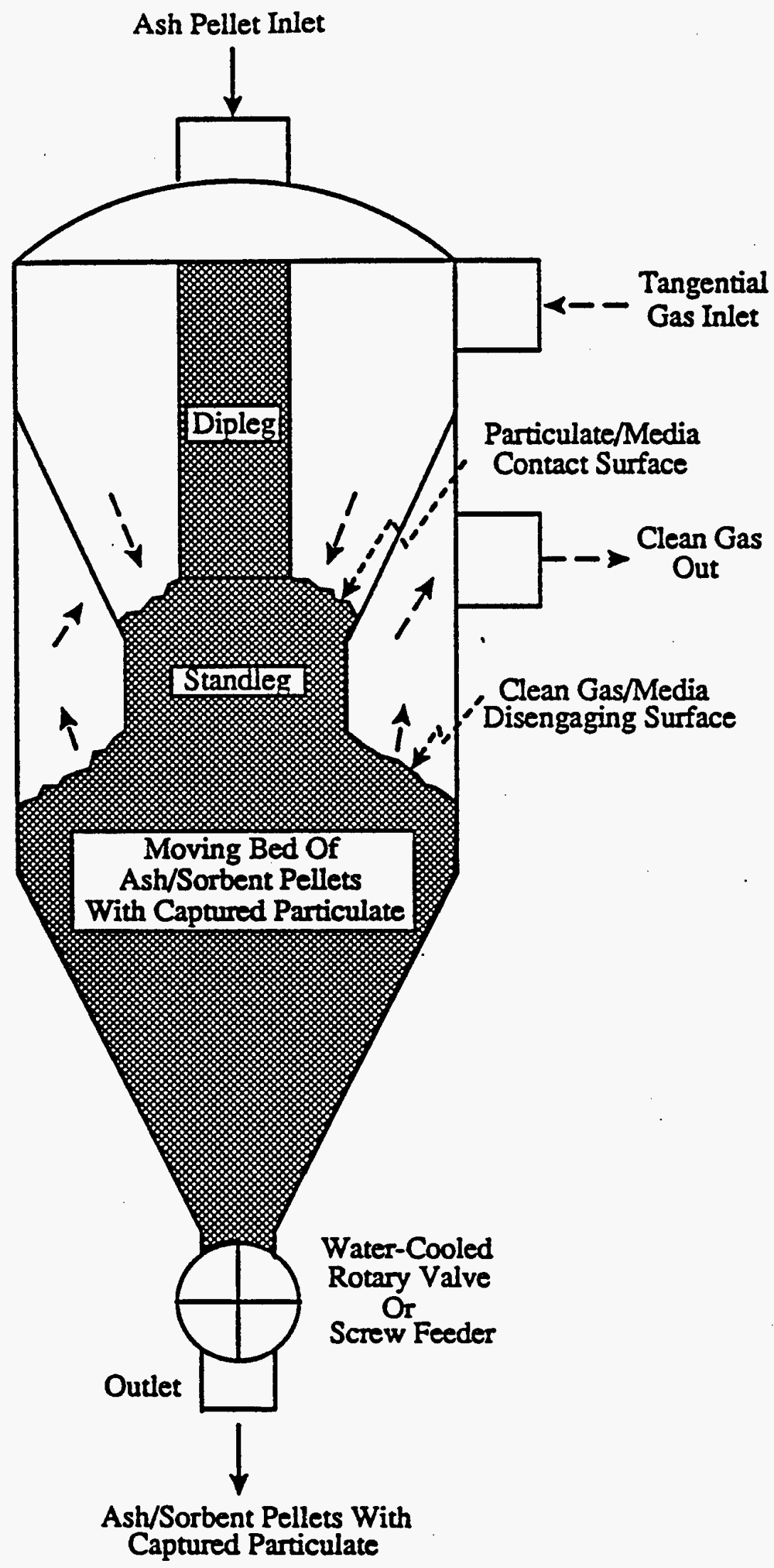

Figure 1-SMGBF Module Schematic 
moving bed media, resulting in excellent separation of fly ash particles. The cocurrent gas/solids operation also prevents fluidization at the bottom of the standleg and permits high flow throughput ( 3 to $6 \mathrm{ft} / \mathrm{s}$ through the standleg), with relatively small ratios of bed media-to-fly ash (mass ratio of about 10). The cleaned gas is then allowed to flow out through the free surface of the bed formed naturally below the standleg. Special design features are built into the region at the base of the standleg to permit disengagement of the cleaned gas from the moving bed media without significant fly ash re-entrainment. The bed media and captured fly ash withdrawal from the filter vessel is controlled by a water-cooled, rotary valve or screw conveyor located below the vessel. The SMGBF vessel design is relatively simple, and it employs well-known design technology, making it cost effective, reliable, and easy to scaleup.

Two approaches for bed media flow can be used, "continuous" flow or "on-off" flow. In the continuous flow approach, the media conveyor operates continuously and the filter bed reaches and remains at a relatively steady condition with the filter bed having a constant pressure drop. In the on-off flow mode, the media conveyor remains off until the filter bed pressure drop reaches a "trigger" value. At the trigger pressure drop, the media conveyor is activated and media flows through the SMGBF at a relatively high rate until the bed pressure drop is reduced to a baseline value. While the net media use rate is about the same for the two techniques, there may be particle removal efficiency advantages with the on-off technique compared to the continuous flow technique. Experimental comparison is required to establish such an advantage.

Two approaches for handling the bed media can be applied to the SMGBF: "Once-Through" media operation, and "Recycle" media operation. Once-Through media operation applies pelletization technology to generate filter pellets from the power plant solid waste materials, and uses these pellets as a "once-through" filtering media to eliminate the need for costly, complex, and large filter media recycling equipment. This pelletizing step also generates a more environmentally acceptable solid waste product and provides the potential to incorporate gas-phase contaminant sorbents into the filtering media. Recycle media operation recirculates granules from the SMGBF bottom withdrawal point to a top feed point, much as in the traditional moving granular bed 
filter approach. The SMGBF system performs this media circulation function by applying standleg, dense-phase flow and pneumatic transport that uses the dirty process gas to carry the granules. The granules are purchased bed media selected for its attrition resistance and its performance as a filtering media.

A general schematic diagram of the Once-Through SMGBF system in PFBC and IGCC applications is shown in Figure 2. The Once-Through SMGBF system is closely integrated with the power plant because of its need to utilize the power plant solid waste as the moving bed filter media while maintaining high power plant performance and economics. The major system components are:

- The SMGBF modules and their connecting piping,

- The plant solid waste handling system (solids cooling and heat recovery, depressurization, transport)

- The pelletization system (size reduction, pelletization)

- The pellet handling system (pressurization, transport, feeding and distribution)

- The pellet/dust cake handling system (cooling and heat recovery, depressurization, transport)

There are several equipment options for each of these system components, and some of them replace system components that would exist in the power plant when using ceramic barrier filters for particulate control. The solids handling systems and pelletization system are generally commercially available components, but their selection is highly dependent on the nature of the solid waste streams, and they may need to be adapted to environments (e.g., high pressure) where they have not been previousiy demonstrated.

The pelletization system is a key system, and many pelletization techniques are available, applying principles of

- Granulation

- Pressure compaction

- Extrusion compaction 

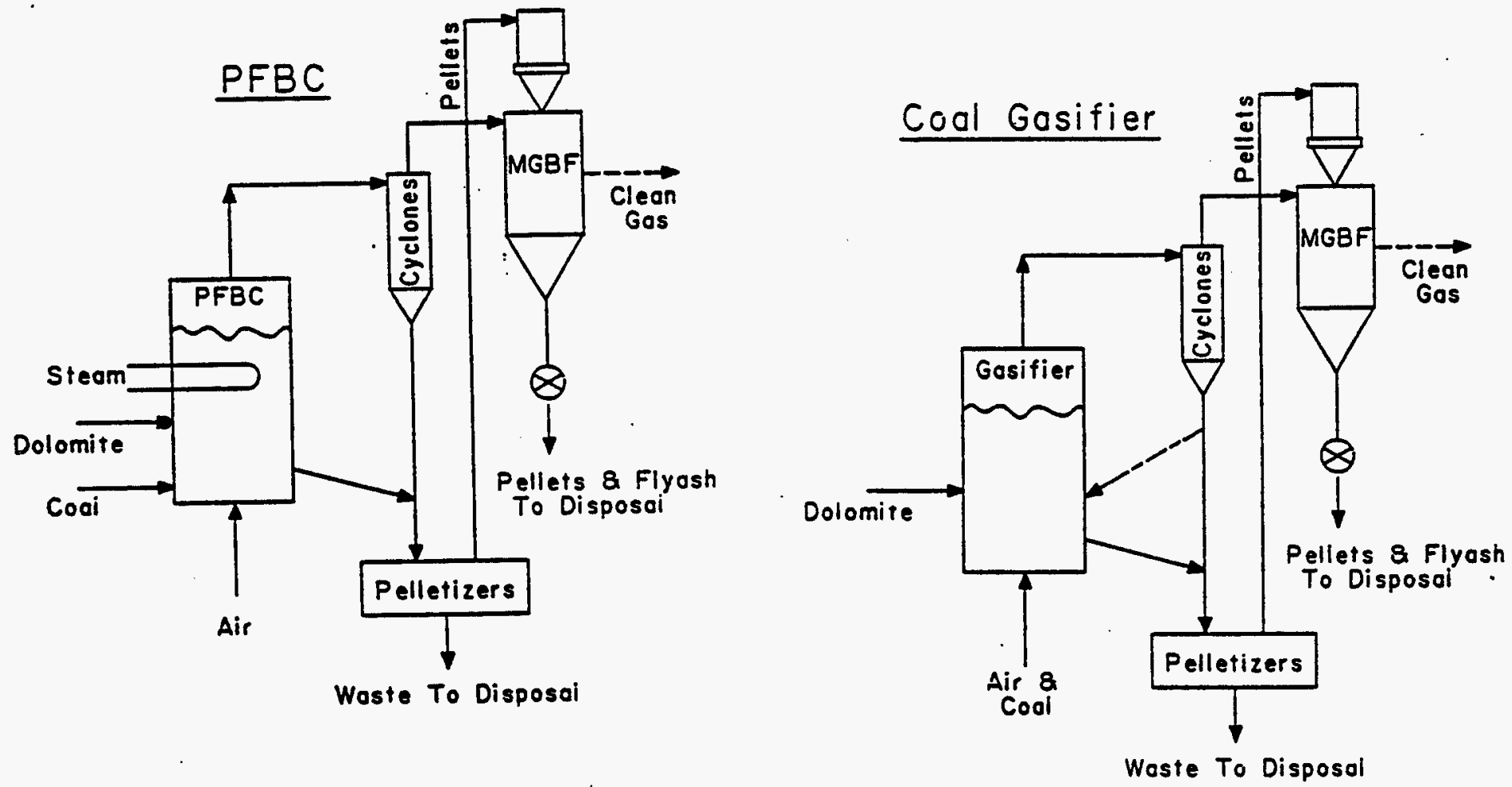

Figure 2 - Once-Through SMGBF System Schematic 
- Agglomeration (with or without binders)

- Globulation (for slags, such as those in some entrained gasifiers and some DCFT)

- Heat bonding

The pelletization system must be integrated into the power plant to minimize complexity and to maximize energy efficiency, as well as being selected to produce sufficiently durable pellets for the SMGBF system.

The Recycle SMGBF system is conceptually illustrated in Figure 3. Granules and captured fly ash are drained from the SMGBF and ash-granule separation is performed to remove a large portion of the captured fly ash. The granules are then aerated in a standleg pipe to increase their pressure so that they may be pneumatically transported back to the entrance of the SMGBF. The SMGBF configuration allows the transport to be accomplished by the dirty, process gas, and fly ash not separated from the granules in the ash-granule separator are reintroduced to the SMGBF.

The SMGBF concept has apparent advantages over conventional granular bed filter technologies, as well as potential advantages over ceramic barrier filter technologies. Relative to conventional granular bed filter technology, the SMGBF is potentially

- More compact, with fewer modules;

- Simpler in design and layout, with no media recycle, or has simplified media recycle;

- Lower in power consumption, with small media feed rate;

- More easily scaled up to commercial size;

- Capable of dealing with plant solid waste issues;

- Higher in performance.

The SMGBF development program has successfully completed the initial, Base Contract period of the four-phase program, and Option 1 of the program has been initiated. The objective of the Base Contract period was to identify the barrier technical 


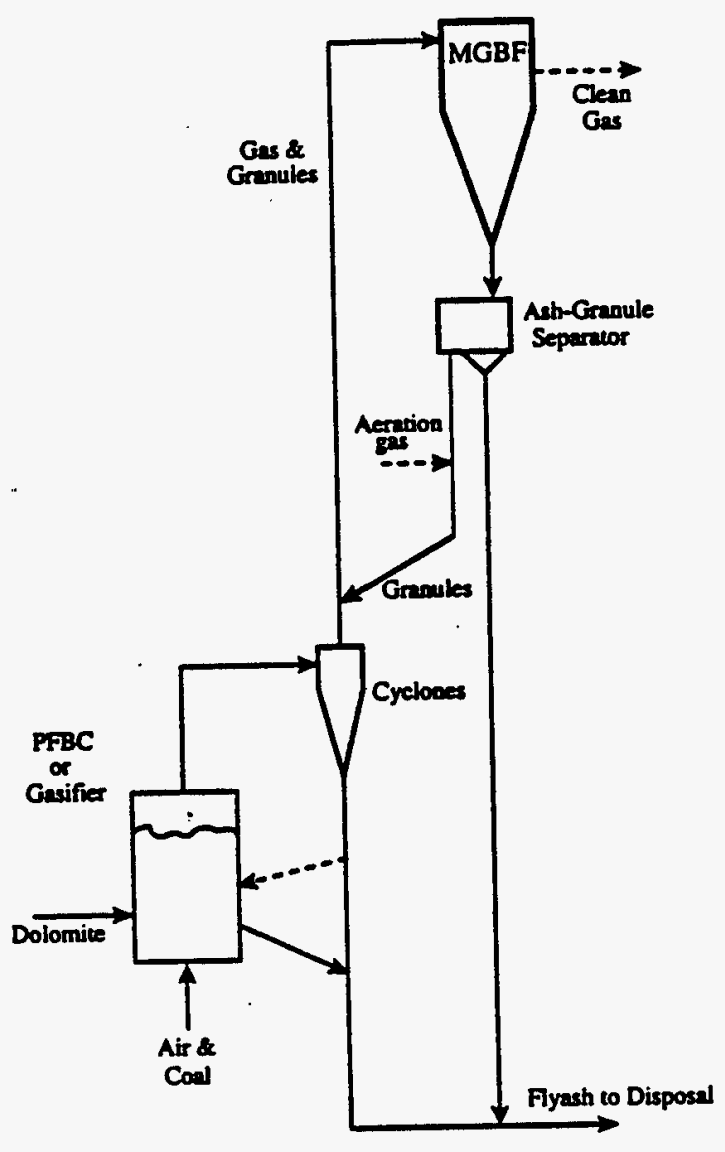

Figure 3-Recycle SMGBF System Concept 
issues and demonstrate conceptual feasibility. The technical approach applied to achieve the Base Contract objective was to conduct 1) commercial plant conceptual design evaluation, in combination with 2) commercial technology assessment, and with 3) laboratory and bench-scale testing subtasks that focussed directly on barrier issues. The objective of the Option 1 program is to optimize the SMGBF performance by evaluating the major technical issues for the technology. The first task in Option 1, Task 8, has identified, defined, and prioritized the technical issues.

This document details the test plan to be performed during the Option 1 to evaluate the technical issues for the SMGBF system. 


\section{SUMMARY AND CONCLUSIONS}

A test plan has been devised for Option 1 Contract period that focuses on the remaining SMGBF technical issues for the purpose of optimizing the SMGBF performance and generating key process performance data needed to promote the continued development of the technology. These technical issues have been identified and ranked in the Task 8, Technical Tradeoffs and Issues Report, submitted to DOE in May, 1994. Three activities are defined in this test plan to address the key issues identified: the first activity performs engineering modeling and design evaluation to support the test activities; the second activity is directed toward SMGBF cold flow model testing; and the third activity is directed toward high-temperature, high-pressure (HTHP) SMGBF testing. All of the activities are directed toward Recycle SMGBF, although much of it also applies to Once-Through SMGBF.

The Option 1 test plan document contains the following information:

- An explanation of:

- the approach applied in the testing,

- how test results will be interpreted.

- A conceptual design description of the component test facilities to be used.

- Descriptions of the test activities:

- objectives

- procedures

- permissible ranges of key parameters

- performance goals

- data to be collected

- test matrices

- Estimated cost of each of the test facilities and the cost of each activity.

- The schedule for the Option 1 test activities. 
The test plan is constrained to consider test variable ranges that are feasible for competitiveness with ceramic barrier filters, and conditions that are representative of PFBC and IGCC. This test plan is based, in-part, on the results of the testing and commercial evaluation of SMGBF performed in the Base Contract and reported in the Base Contract Topical Report of April 1994.

The total cost of the materials and equipment, installation labor, and test operation labor for the Option 1 program is about $\$ 350,000$. 


\section{OPTION 1 APPROACH}

Testing in Option 1 is focused on resolving the remaining SMGBF technical issues, leading to process performance improvements, advanced system and component features, and economic optimization. The approach applied in Option 1 is to concentrate the Option 1 resources on Recycle SMGBF because of its greater general applicability over Once-Through SMGBF. Test conditions (design and operating parameters) and component features are selected that fall within the realm of acceptability for economical competitiveness with ceramic barrier filters, and that are representative of the PFBC and IGCC environments. Engineering modeling and design evaluation is used in Option 1 to support the selection of appropriate component features and test conditions, and for the interpretation of test results.

The activities defined are:

1. Engineering modeling and evaluation

2. Cold flow model testing

3. HTHP performance testing

The first activity, engineering modeling and evaluation, models the flow and distribution of gas, bed media, and fly ash through the SMGBF vessel, and applies the modeling to project SMGBF performance to large, commercial-scale capacities. This scaleup evaluation defines the limits of module capacity, and allows test results to be interpreted for commercial conditions. The activity also produces conceptual designs of some major SMGBF system components and identifies the conditions of their testing. The components considered are:

- the topping, or secondary, bed,

- the granule recirculation system,

- the ash-granule separator 
The second activity, cold flow model testing, will modify the existing cold flow model equipment to look at advanced features of Recycle SMGBF. The cold flow model testing activity will also produce basic probe data used to substantiate the engineering modeling performed in the first activity. The particle removal performance and pressure drop characteristics of the SMGBF will be measured at conditions representing PFBC and IGCC environments (similar fly ash loadings, fly ash types, bed media to fly ash mass ratio), with the gas flow limited to economically feasible ranges (3-6 ft/s through the standleg).

The final activity, HTHP filter performance testing, is a demonstration test of the HTHP, SMGBF performance based on the special design and operating features identified in the cold flow model testing. The HTHP equipment will be modified to incorporate the improved features identified in the cold model testing as well as to improve the general test operation of the facility. The HTHP testing will be performed using PFBC fly ash injected into the HTHP gas stream. The HTHP test system will be operated under oxidizing conditions only. The basic concept feasibility, primarily particle removal performance, pressure drop, and operability, are to be demonstrated at representative conditions using economically-limited test variables. 


\section{INTERPRETATION OF TEST RESULTS}

The interpretation of the tests must be directed toward the technical issues identified for the Recycle SMGBF system. The engineering modeling and design evaluation activity will produce perspective and tools needed to properly interpret the test results. Cold flow model testing will be carried out at a scale approaching 1/10-th of the commercial module diameter, and the test measurements will be scaled to high-temperature, high-pressure conditions, and full-scale dimensions using the engineering modeling performed in the first activity. The performance of the cold model must be acceptable in terms of pressure drop, and particle emissions. Representative performance limits are, when scaled to HTHP conditions:

maximum pressure drop (psi):

maximum particle emission (ppmw):

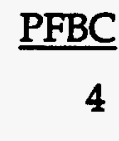

20 $\underline{\text { IGCC }}$

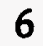

100

and it is the goal of the program to significantly exceed these performance levels.

The HTHP testing will be at a smaller scale than the cold flow modeling (a factor of 2 smaller in standleg diameter), and will be interpreted directly with respect to particle removal efficiency and pressure drop. System operability and reliability will also be assessed in the testing, comparing startup and other transient condition limitations with those for ceramic barrier filters. 


\section{DESIGN OF COMPONENT TEST FACILITIES}

Designs for the SMGBF cold flow facility and for the HTHP filter facility are shown, and descriptions of the major features are presented in this section.

\subsection{Cold Flow Facility}

Figure 4 is a layout drawing of the existing SMGBF cold flow model. The central view of the vessel shows the vessel cross-sectioned internals. The dirty gas enters tangentially at the vessel aluminum top piece, and an optional radial inlet is also available. The bed media enter through a dipleg arranged axially at the top of the vessel. The gas flows cocurrently downward with the bed media through the Plexiglas cone section, then through the $1 \mathrm{ft}$ diameter standleg section at a maximum design velocity of $6 \mathrm{ft} / \mathrm{s}$. At the exit from the standleg the gas turns to flow upward, disengaging from the bed media, and exits radially from the vessel. An alternative gas outlet is shown in the bottom Plexiglas section to provide flexibility for the outlet location. Use of this alternative gas outlet requires the two Plexiglas sections to be rearranged.

The Plexiglas standleg is supported by a ring located at the tip of the standleg, and this ring has eight holes inserted for the exit gas to pass through. The bed media flows out of the conical bottom of the vessel. The base of the standleg is designed so that alternative features may be added to assist in the disengagement of the gas from the bed media, and/or for limiting local fluidization and fly ash entrainment.

The Plexiglas is $1 "$ thick and the design pressure is 10 psig. Reinforcement beams also support the Plexiglas vessel wall.

The arrangement drawing of the existing cold flow facility also shows the bed media feeding and withdrawal equipment arrangement within the high-bay test area. A storage and feed bin is located at the top, and a slide valve is used to shut off the bed media flow from the bin. The Plexiglas SMGBF unit is directly under the bed media feed bin. The conical outlet from the cold model passes bed media into a screw conveyor that 
loads the bed media into 55-gal drums for storage. The screw conveyor controls the rate of bed media flow through the cold model. The method for loading the bed media into the feed bin is the load-and-lift approach, with the feed bin lowered to the floor level, loaded with bed media dumped from 55 -gal drums, and then lifted by hoist to its feeding position above the cold flow model.

The P\&ID for the existing cold flow model test facility is shown in Figure 5. The major components are an air blower system and air supply system; the Plexiglas model; the bed media handling, feeding, and withdrawal equipment, the fly ash feeding system, and the air exhaust system with their associated flow controls and instrumentation for temperature, pressure, and pressure drop measurements. The air exhaust system includes a conventional fabric filter that will collect particulate material as a batch collection for the determination of the SMGBF fly ash penetration.

The maximum flow rates of the major process streams in the test program are:

- Air flow: 283 acfm

- Fly ash flow: $6 \mathrm{lb} / \mathrm{hr}$

- Bed media flow: about $100 \mathrm{lb} / \mathrm{hr}$

Several modifications will be made to the cold flow facility for the Option 1 test program.

\section{Standleg Configuration}

Several standleg configurations have been identified that may significantly improve the SMGBF particle removal performance, or may improve the test data quality, and these will be fabricated for testing in Option 1:

- A metal inlet cone and a 3-ft long, metal standleg will be provided in place of the current Plexiglas cone and standleg. This will eliminate the interference produced by the support ring structure on the current Plexiglas pieces and will improve the quality of the model simulation. 


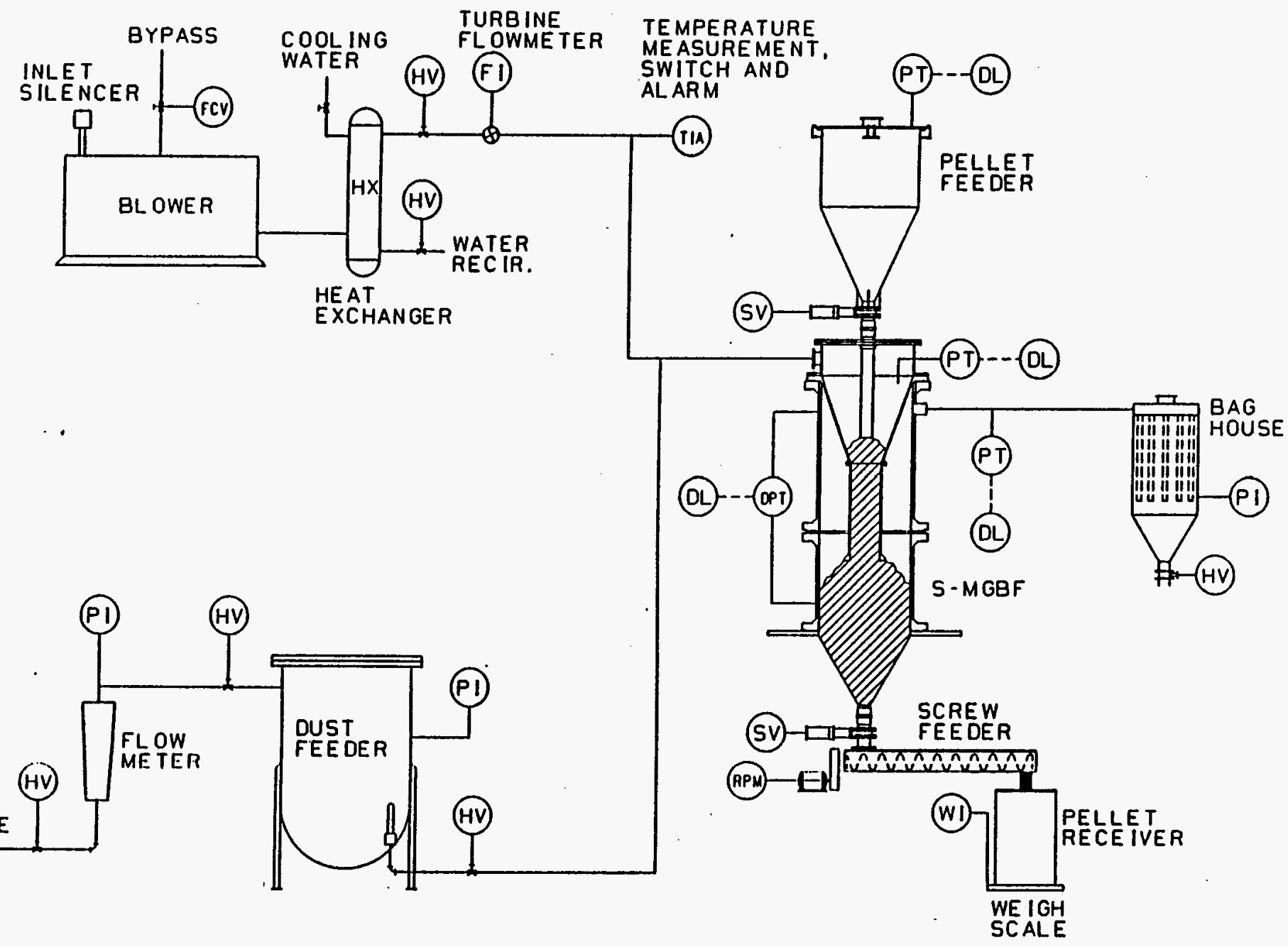

Figure 5 - Cold Model System P\&ID 
- A metal, cylindrical standleg section having 2-ft length will be fabricated for use as a test parameter.

- A metal, skirt section having no perforations will be fabricated, to be used in place of the current perforated skirt section as a test parameter.

- A metal, conically-shaped standleg will be fabricated for use as a test parameter.

- A metal, standleg with perforations will be fabricated for use as a test parameter.

The variations in standleg configurations to be fabricated and tested in Option 1 are illustrated in Figure 6. Engineering modeling will be performed to develop the expected best design features of each of these.

\section{Bed Media Recirculation System}

A granule recirculation system will be provided, consisting of an ash-granule separator (vibrator type), and a pneumatic transport line back to the SMGBF gas inlet plenum, to simulate the Recycle SMGBF system. The bed media circulation system is illustrated in Figure 7.

\section{Topping Bed Configuration}

Topping bed concepts have been identified as having potential benefits for the SMGBF performance, and limited testing was performed in the Base Contract to confirm this. Special features to allow a continuously-fed topping bed, of a fixed topping bed will be fabricated, their design selected, in-part, from the engineering evaluation activity. These features are conceptually illustrated in Figure 8. 


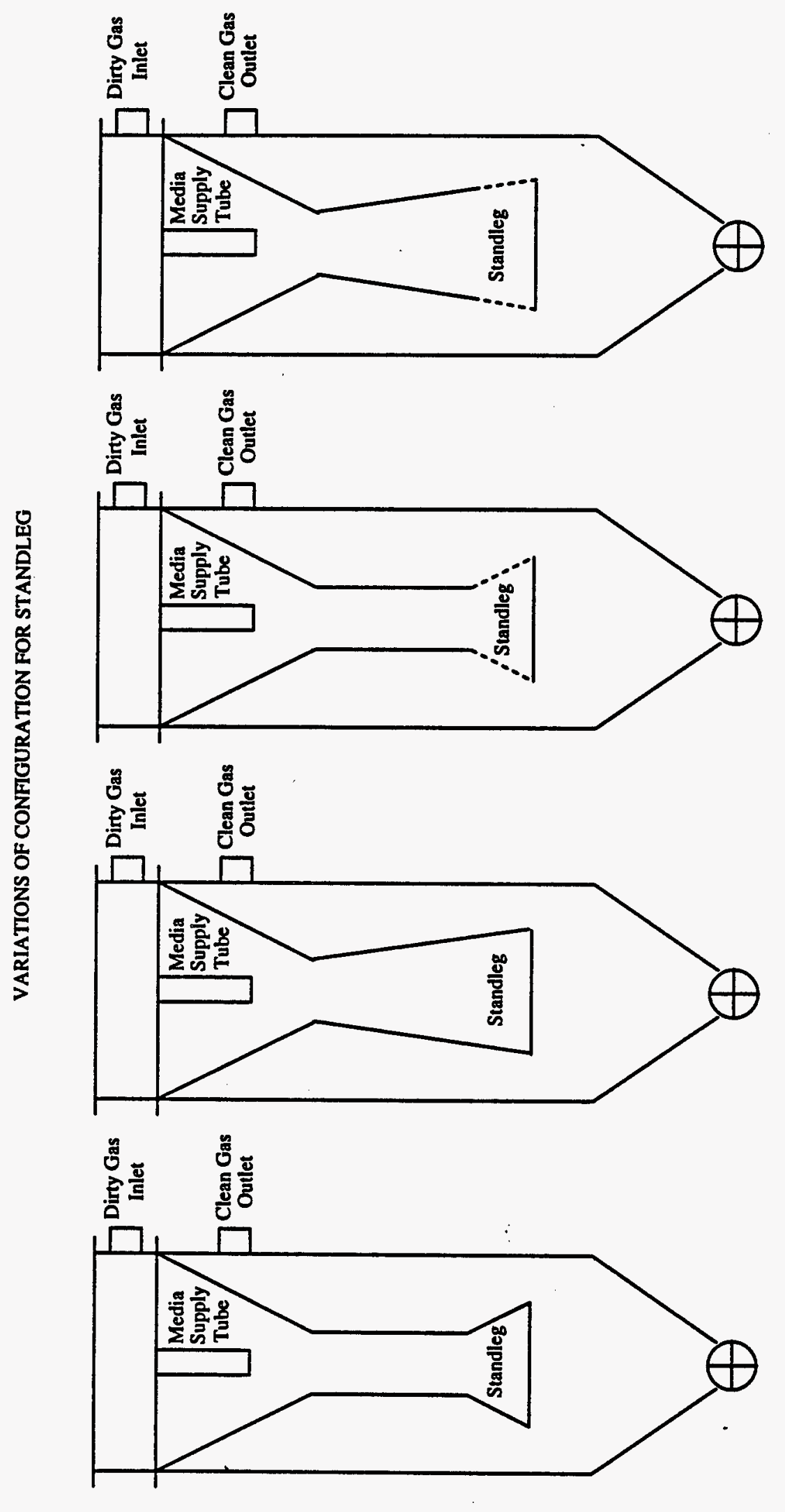

ह 


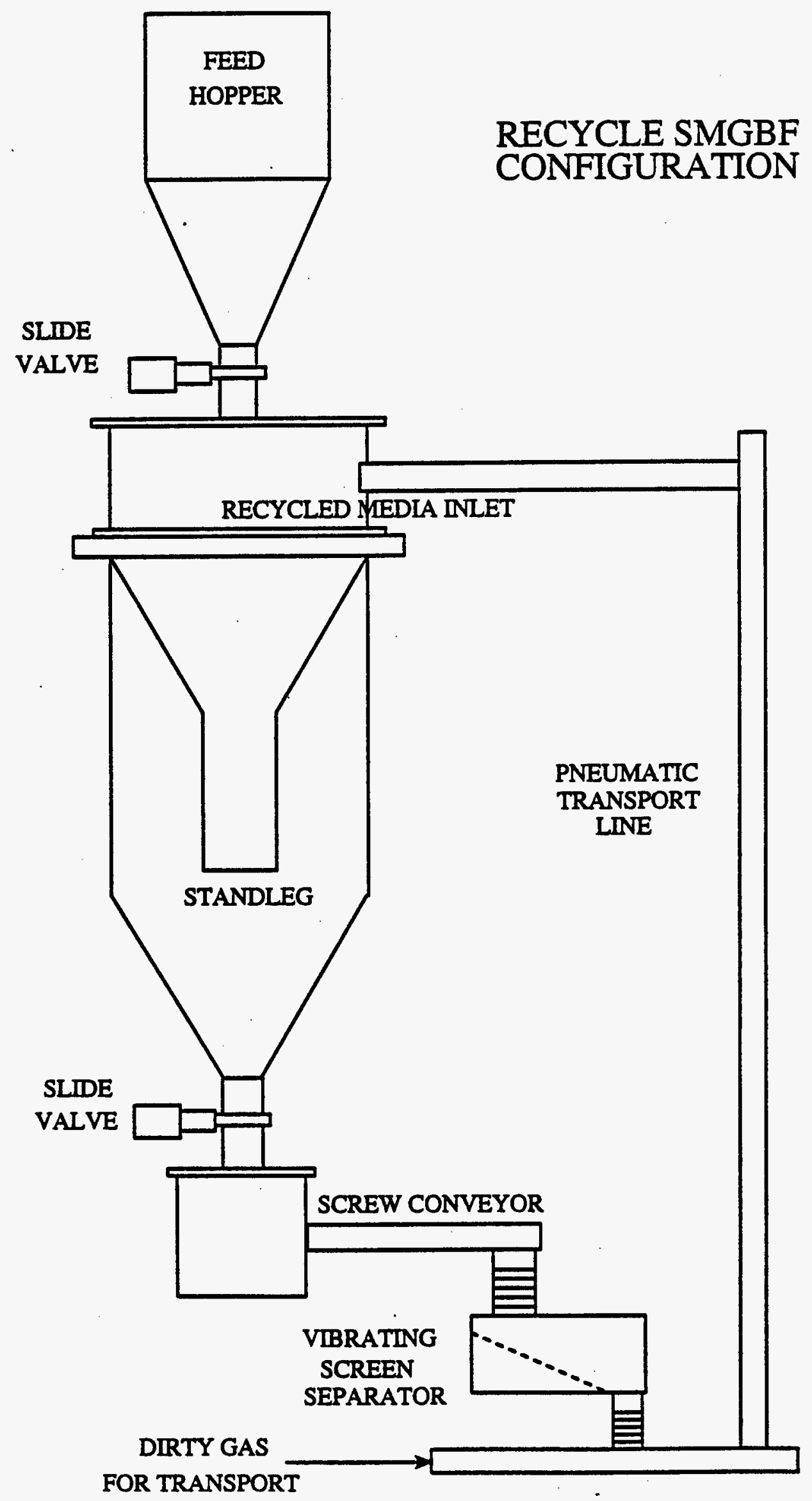

Figure 7 - Cold Model Bed Media Recirculation System 
VARIATIONS OF CONFIGURATION FOR STANDLEG WITH INNER AND OUTER BEDS
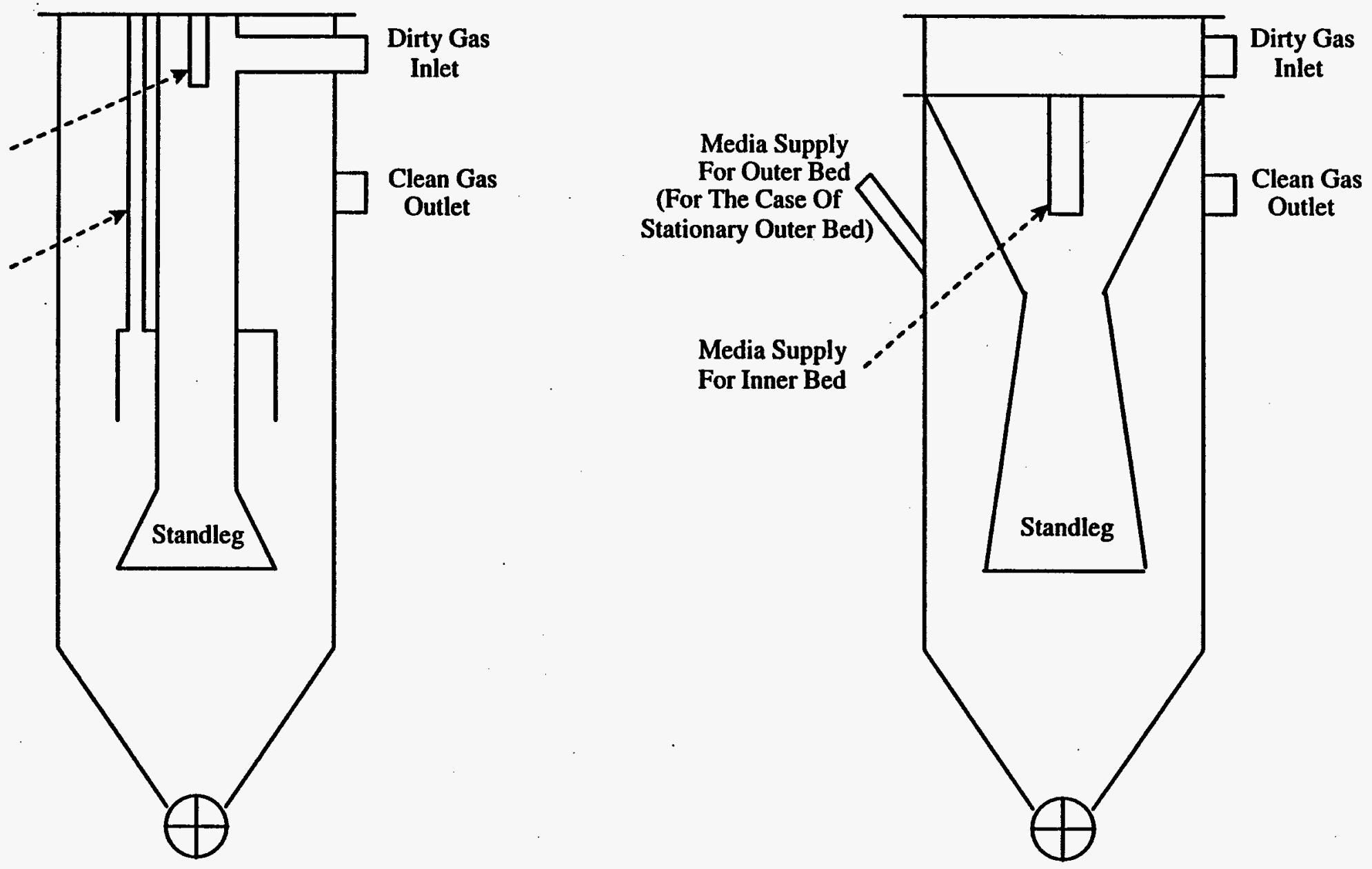

Figure 8-Cold Model Topping Bed Configurations 


\subsection{HTHP Test Facility}

Figure 9 is a conceptual layout drawing and P\&ID for the auxiliary systems of the existing SMGBF HTHP test facility. The pressure vessel is a refractory-lined vessel used previously for ceramic barrier filter testing. The pressure vessel head was modified to accommodate the top gas inlet location and the support of the vessel internals. The essential vessel features are identical with those described for the cold model, except the vessel and internals are designed for operation at $1600^{\circ} \mathrm{F}$ and up to 350 psig pressure. The dirty gas enters tangentially into the vessel. As in the cold model, an alternative radial gas inlet has been included in the head. The bed media and gas pass cocurrently downward through the high-alloy cone and standleg pieces, and gas disengagement occurs at the base region of the standleg. The standleg has a 6 " diameter in this vessel, so the HTHP unit has $1 / 4$ of the cold model actual volumetric flow. The bed media and collected fly ash pass out through the conical base.

The internal support structure within the vessel for the cone and standleg pieces is similar in design to the tube sheet used in the ceramic barrier filters. The expansion web accommodates the thermal expansion of the materials. The gas seals are located at the cold vessel flange.

Figure 10 shows the conceptual arrangement of the major equipment in the HTHP test facility. A batch loaded, pressurized bed media feed bin is located above the vessel. A high-temperature valve (eg., water-cooled screw) controls the flow rate of bed media through the unit, and feeds the bed media into a pressurized storage hopper. Hot combustion gases are generated by a natural gas fired combustor, and fly ash is injected into the combustion products before entering the filter vessel. A K-Tron screw feeder contained in a pressure vessel is used to control and measure the fly ash feed rate. Water-cooled piping carries the exhaust gas from the vessel to the pressure letdown valve, and the building exhaust. 


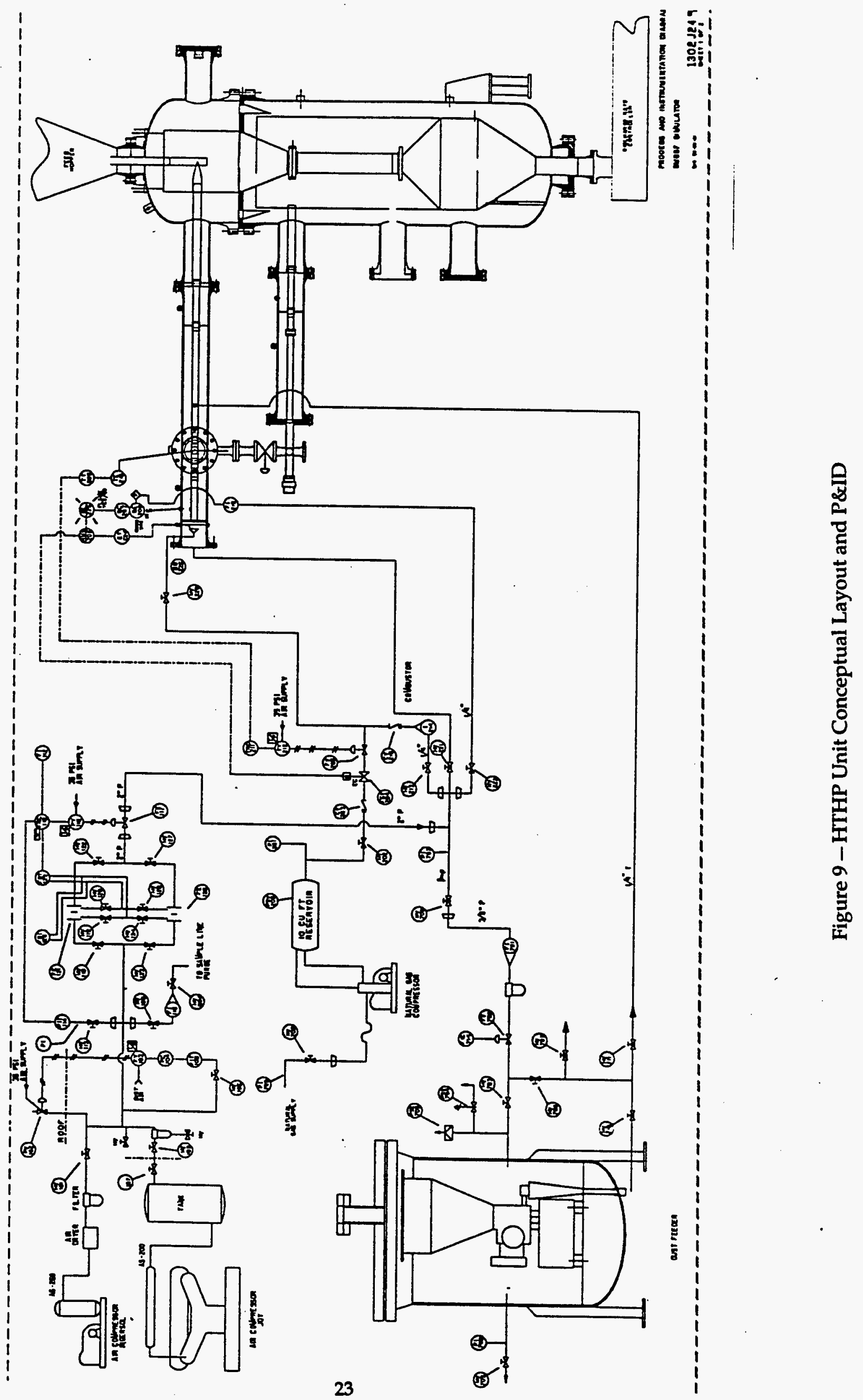


The HTHP test facility has two air compressors that can supply up to 1500 $\mathrm{lb} / \mathrm{hr}$ of air at up to $200 \mathrm{psig}$. A natural gas compressor supplies the high pressure natural gas for the combustor. The air stream is split so part of it goes to the combustor and part of it goes to the fly ash feeder. The fly ash feed is injected just downstream of the combustor so it can be heated before entering the upper end of the SMGBF. Provisions for measuring temperatures, pressures and differential pressures are available. A computer based data logging system is used to collect and display the data during testing and to reduce it after the test.

The maximum flow rates of the major process streams in the test program are:

- Gas flow: $71 \mathrm{acfm}$, or $820 \mathrm{lb} / \mathrm{hr}$

- Fly ash flow: $4 \mathrm{lb} / \mathrm{hr}$

- Bed media flow: about $80 \mathrm{lb} / \mathrm{hr}$

For the Option 1 testing, the following changes will be made to the HTHP facility:

- An enlarged, higher capacity bed media feed system will be procured and installed. Provision will be provided to allow feeding of bed media to the process gas inlet stream so that this aspect of the Recycle SMGBF system can be tested.

- New vessel internals will be fabricated (for example, standleg, skirt, other baffles) based on the cold flow model testing results.

- A separate, laboratory device to study ash-granule separation of hot ashgranule mixtures withdrawn from the HTHP unit will be assembled for testing. 


\section{DESCRIPTION OF ENGINEERING MODELING AND EVALUATION ACTIVITIES}

\section{Objectives}

The objectives of this first activity, engineering modeling and evaluation, are to 1) produce a modeling tool of the flow and distribution of gas, bed media, and fly ash through the SMGBF vessel, 2) apply this modeling to project SMGBF performance at large, commercial-scale capacities, and 3) generate conceptual designs of the major SMGBF system components to determine their appropriate test conditions.

\section{Approach}

Engineering modeling, using available correlations and conceptual descriptions of the major phenomena in the SMGBF system, can be applied to produce rough, though meaningful tools to project performance and scaleup trends. This scaleup evaluation defines the limits of module capacity, and allows test results to be interpreted for commercial conditions. Engineering evaluation of key system components can be performed using standard design procedures and sizing techniques to estimate the features and required operating conditions of the equipment. The key components considered are:

- the topping, or secondary, bed,

- the granule recirculation system,

- the ash-granule separator

Only a low-level of effort is expended on this activity to provide an initial perspective on the scaleup performance and the key component design conditions to act as a guide for test plan development and test result interpretation. 


\section{DESCRIPTION OF COLD FLOW MODEL TESTING}

\section{Objectives}

The objectives of the Option 1 cold flow model testing are:

- Gain insights into operating characteristics, pressure drop profile, solids/gas flow pattern and distribution, solids flow control, operating modes, fly ash reentrainment and accumulation, fluidization at bottom of the standleg, and requirements for special design features to improve gas-particle disengagement at bottom of the standleg.

- Optimize performance (particle removal and pressure drop) at commercially acceptable operating conditions by identifying and testing advanced design features.

- Perform specific measurements of gas flow, bed media flow, and fly ash flow and distribution within the SMGBF to be used to substantiate the engineering models produced in the first activity.

\section{Procedures}

Following completion of the cold flow model equipment modifications, a series of tests will be conducted with variations in major operating variables and design parameters. All of these tests will measure pressure drop profiles through the SMGBF, will determine the particle collection efficiency, and will visually observe the behavior of gas, bed media, and fly ash within the SMGBF unit. Test series will be conducted to look at Recycle SMGBF behavior.

The fly ash feeder will be first calibrated with the fly ash to be used in the tests. The screw feeder for bed media flow control will also be calibrated by feeding bed media into a 55-gal drum on a weight scale. The air flow into the cold flow model will be measured with a turbine flow meter. 
The primary test program consists of tests with fly ash injection. The fly ash collection efficiency will be evaluated by the difference between the fly ash delivered and the fly ash collected in the exhaust gas filter. Similarly, the fly ash loading in the gas can be calculated from the fly ash delivered and the gas flow rate. The moving bed velocity will be calculated from the weight collected in the 55-gal drum over the duration of the run. All pressure drops and gas flows will be monitored continuously and recorded for further analysis. Tests of Recycle SMGBF will also monitor the ash-granule separator performance, the pneumatic transport line performance, and the behavior of granules injected into the SMGBF gas inlet plenum.

Special measurements will be performed during several of the tests to determine gas flow profiles in the SMGBF, particularly in the vicinity of the gas-bed media disengaging zone. The general motion of bed media through the unit will also be measured. Finally, probe core samples will be withdrawn from various regions of the SMGBF unit to determine the pattern of fly ash accumulation within the unit. These detailed measurements will be used to calibrate and substantiate the engineering models generated in Option 1.

\section{Permissible Ranges of Key Parameters}

The parameters to be varied in the testing are:

- the SMGBF configuration,

- recycle mode

- with and without topping bed

- the skirt design,

- the standleg length,

- the bed media/fly ash mass ratio,

- the bed media.

The gas velocity selected for the testing covers the range of permissible parameters based on economic competitiveness with ceramic barrier filters. "The moving bed velocities and bed media to fly ash mass flow ratios represent values that can be economically achieved in PFBC and IGCC applications. 
The operating and design condition range is limited as outlined below:

pressure

temperature

Operating modes

Gas face velocities

Bed media/fly ash mass

Fly ash loading

Bed media material

Fly ash material
- 15 psia

- less than $100^{\circ} \mathrm{F}$

- recycle mode

- $\quad 3$ to $6 \mathrm{ft} / \mathrm{s}$ through the standleg

- 10 to 20

- $\quad 5000-10,000$ ppm by weight

- crushed acrylic, dolomite, and pellets from PFBC or IGCC waste, or from representative substitutes.

- $\quad$ PFBC fly ash

\section{Data to be Collected}

The gas flow, solids flow, and pressure drop across the standleg will be continuously monitored. The fly ash delivered will be determined through mass balance on the loss-in-weight dust feeder. The gas flow will be measured with a turbine flow meter and the bed media flow determined from the weight gain in the 55-gal drum located at the outlet of the screw feeder. The screw feeder will be calibrated beforehand for solids flow control. From those measurements, the fly ash loading, the gas face velocity, the moving bed velocity, and the fly ash collection efficiency can be derived.

Pressure drop profile across the standleg and the absolute pressure at dirty gas inlet and clean gas outlet will be measured with pressure transducers or gages for further analysis. Smoke injection for visual observation and video taping may also be employed to document some of the tests.

-Visual observations of fly ash accumulation patterns in the moving bed, local fluidization, bed media flow patterns, and regions of gas bypassing will be made. All of the observations made in the cold flow model will be scaled to HTHP conditions to provide interpretation of the results. 


\section{$\underline{\text { Test Matrix }}$}

A tentative test matrix shown in Table 1 will be conducted. A total of 19 tests are identified in the matrix. The specific test conditions are subject to change depending on the trends shown by the data during testing. Additional variations in the variables, such as the testing of higher standleg velocities will also be tested depending on the performance results and the availability of funds. 
Table 1 - SMGBF Option 1 Test Matrix

\begin{tabular}{|c|c|c|c|c|c|c|c|c|c|}
\hline $\begin{array}{l}\text { RUN } \\
\text { NUMBER }\end{array}$ & $\begin{array}{c}\text { SMGBF } \\
\text { CONFIGURATION } \\
\end{array}$ & $\begin{array}{l}\text { SKIRT } \\
\text { DESIGN } \\
\end{array}$ & $\begin{array}{l}\text { STANDLEG } \\
\text { LENGTH }\end{array}$ & $\begin{array}{l}\text { STANDLEG } \\
\text { DIAMETER }\end{array}$ & $\begin{array}{l}\text { GRAN./ASH } \\
\text { FEED RATIO } \\
\end{array}$ & $\begin{array}{l}\text { GAS FACE } \\
\text { VELOCITY }\end{array}$ & $\begin{array}{l}\text { BED } \\
\text { MEDIA }\end{array}$ & $\begin{array}{c}\text { RUN } \\
\text { DURATION } \\
\end{array}$ & COMMENTS \\
\hline 1 & Standard & $\begin{array}{l}\text { Cone with } \\
\text { Perforation }\end{array}$ & $3 \mathrm{ft}$ & $1 \mathrm{ft}$ & 20 & $3 \mathrm{ft} / \mathrm{s}$ & $\begin{array}{l}\text { Crushed } \\
\text { Acrylic }\end{array}$ & $15 \mathrm{hr}$ & Use dirty bed media \\
\hline $2-1$ & Standard & $\begin{array}{c}\text { Cone w/o } \\
\text { Perforation }\end{array}$ & $3 \mathrm{ft}$ & $1 \mathrm{ft}$ & 10 & $3 \mathrm{ft} / \mathrm{s}$ & $\begin{array}{l}\text { Crushed } \\
\text { Acryllic }\end{array}$ & $15 \mathrm{hr}$ & Use dirty bed medla \\
\hline $2-2$ & Standard & $\begin{array}{l}\text { Cone w/o } \\
\text { Perforation }\end{array}$ & $3 \mathrm{ft}$ & $1 \mathrm{ft}$ & 20 & $3 \mathrm{ft} / \mathrm{s}$ & $\begin{array}{l}\text { Crushed } \\
\text { Acryllic }\end{array}$ & $15 \mathrm{hr}$ & $\begin{array}{l}\text { This run may not be conducted, } \\
\text { depending on the results of Run 2-1. }\end{array}$ \\
\hline 3 & Standard & $\begin{array}{l}\text { Cone with } \\
\text { Perforation }\end{array}$ & $2 \mathrm{ft}$ & $1 \mathrm{ft}$ & 20 & $3 \mathrm{ft} / \mathrm{s}$ & $\begin{array}{l}\text { Crushed } \\
\text { Acrylic }\end{array}$ & $15 \mathrm{hr}$ & Use dirty bed media \\
\hline 4 & Standard & $\begin{array}{l}\text { Conical } \\
\text { Standleg }\end{array}$ & $3 \mathrm{ft}$ & Ift & 10 & $3 \mathrm{ft} / \mathrm{s}$ & $\begin{array}{l}\text { Crushed } \\
\text { Acrylic }\end{array}$ & $15 \mathrm{hr}$ & Use dirty bed medla \\
\hline $5-1$ & Standard & $\begin{array}{l}\text { Cone with } \\
\text { Perforation }\end{array}$ & 2 or $3 \mathrm{ft}$ & $1 \mathrm{ft}$ & 10 & $3 \mathrm{ft} / \mathrm{s}$ & Dolomile & $15 \mathrm{hr}$ & \\
\hline $5-2$ & Standard & $\begin{array}{l}\text { Cone with } \\
\text { Perforalion }\end{array}$ & 2 or $3 \mathrm{ft}$ & $1 \mathrm{ft}$ & 10 & $3 \mathrm{ft} / \mathrm{s}$ & Pellels & $15 \mathrm{hr}$ & $\begin{array}{l}\text { This run may not be conducted, } \\
\text { depending on availability of pellels. }\end{array}$ \\
\hline$\overline{6}$ & Topping Bed & $\begin{array}{l}\text { Cone with } \\
\text { Perforation }\end{array}$ & $3 \mathrm{ft}$ & $1 \mathrm{ft}$ & 10 & $3 \mathrm{ft} / \mathrm{s}$ & $\begin{array}{l}\text { Crushed } \\
\text { Acryllc }\end{array}$ & $15 \mathrm{hr}$ & Use clean material for topping bed \\
\hline 7 & Topping Bed & $\begin{array}{l}\text { Cone with } \\
\text { Perforation }\end{array}$ & $2 \mathrm{ft}$ & Ift & 10 & $3 \mathrm{fts}$ & $\begin{array}{l}\text { Crushed } \\
\text { Acryllic }\end{array}$ & $15 \mathrm{hr}$ & Use clean material for topping bed \\
\hline 8 & Topping Bed & $\begin{array}{l}\text { Standleg with } \\
\text { Perforation }\end{array}$ & $3 \mathrm{ft}$ & $1 \mathrm{ft}$ & 10 & $3 \mathrm{ft} / \mathrm{s}$ & $\begin{array}{l}\text { Crushed } \\
\text { Acryllc }\end{array}$ & $15 \mathrm{hr}$ & Use clean malerial for toppling bed \\
\hline 9 & Topping Bed & TBD & 2 or $3 \mathrm{ft}$ & $1 \mathrm{ft}$ & 20 & $3 \mathrm{ft} / \mathrm{s}$ & $\begin{array}{l}\text { Crushed } \\
\text { Acrylic }\end{array}$ & $15 \mathrm{hr}$ & Use clean material for lopping bed \\
\hline $10-1$ & Topping Bed & TBD & 2 or $3 \mathrm{ft}$ & Ift & 10 & $3 \mathrm{f} / \mathrm{s}$ & Dolomite & $15 \mathrm{hr}$ & Use clean material for fopping bed \\
\hline $10-2$ & Topping Bed & TBD & 2 or $3 \mathrm{ft}$ & $1 \mathrm{ft}$ & 10 & $3 \mathrm{ft} / \mathrm{s}$ & Pellets & $15 \mathrm{hr}$ & $\begin{array}{l}\text { This run may not be conducted, } \\
\text { depending on availability of pellets. }\end{array}$ \\
\hline $11-1$ & $\begin{array}{c}\text { Standard } \\
\text { Reclirculating Bed }\end{array}$ & $\begin{array}{l}\text { Cone with } \\
\text { Perforation }\end{array}$ & $3 \mathrm{ft}$ & $1 \mathrm{ft}$ & 10 & $3 \mathrm{ft} / \mathrm{s}$ & $\begin{array}{l}\text { Crushed } \\
\text { Acryllic }\end{array}$ & $15 \mathrm{hr}$ & Use dirty bed media \\
\hline $11-2$ & $\begin{array}{c}\text { Standard } \\
\text { Recirculating Bed } \\
\end{array}$ & $\begin{array}{l}\text { Cone with } \\
\text { Perforation }\end{array}$ & $3 \mathrm{ft}$ & $1 \mathrm{ft}$ & 20 & $3 \mathrm{ft} / \mathrm{s}$ & $\begin{array}{l}\text { Crushed } \\
\text { Acrylic }\end{array}$ & $15 \mathrm{hr}$ & $\begin{array}{l}\text { This run may nof be conducted, } \\
\text { depending on prior lest results. }\end{array}$ \\
\hline 12 & $\begin{array}{c}\text { Topping } \\
\text { Recirculating Bed }\end{array}$ & $\begin{array}{l}\text { Cone with } \\
\text { Perforation }\end{array}$ & $3 \mathrm{ft}$ & $1 \mathrm{ft}$ & 10 & $3 \mathrm{ft} / \mathrm{s}$ & $\begin{array}{c}\text { Crushed } \\
\text { Acrylic }\end{array}$ & $15 \mathrm{hr}$ & Use clean bed material for topping bed \\
\hline 13. & $\begin{array}{c}\text { Topping } \\
\text { Recirculating Bed }\end{array}$ & $\begin{array}{l}\text { Standleg with } \\
\text { Perforatlon }\end{array}$ & $3 \mathrm{ft}$ & $1 \mathrm{ft}$ & 10 & $3 \mathrm{f} / \mathrm{s}$ & $\begin{array}{l}\text { Crushed } \\
\text { Acrylic }\end{array}$ & $15 \mathrm{hr}$ & Use clean bed material for topping bed \\
\hline 14 & $\begin{array}{c}\text { Topping } \\
\text { Recirculating Bed } \\
\end{array}$ & TBD & $3 \mathrm{ft}$ & $1 \mathrm{ft}$ & 10 & $3 \mathrm{ft} / \mathrm{s}$ & Dolomile & $15 \mathrm{hr}$ & Use clean bed material for topping bed \\
\hline 15 & $\begin{array}{c}\text { Topping } \\
\text { Recirculating Bed } \\
\end{array}$ & TBD & $3 \mathrm{ft}$ & $1 \mathrm{ft}$ & 10 & $3 \mathrm{ft} / \mathrm{s}$ & Pellets & $15 \mathrm{hr}$ & $\begin{array}{l}\text { This run may not be conducted, } \\
\text { depending on availability of pellets. }\end{array}$ \\
\hline
\end{tabular}

NOTES: (1). All bed configurations and experimental conditions are subjected to changes depending on experimental results.

(2). Additional lests may be pertormed at higher gas face velocittes if schedule and fund permit. 


\section{DESCRIPTION OF HTHP PERFORMANCE TESTING}

\section{Objectives}

The objectives of the Option 1 HTHP performance tests are:

- Demonstrate the HTHP, SMGBF performance based on the special design and operating features identified in the cold flow model testing.

- Demonstrate acceptable fly ash removal performance at commercially acceptable, and representative operating conditions.

\section{Procedures}

The HTHP equipment will be modified to incorporate the improved features identified in the cold model testing as well as to improve the general test operation of the facility. The HTHP testing will be performed using PFBC fly ash injected into the HTHP gas stream. The HTHP test system will be operated under oxidizing conditions only. The basic concept feasibility, primarily particle removal performance, pressure drop, and operability, are to be demonstrated at representative conditions using economicallylimited test variables.

The primary test program consists of tests with fly ash injection representative of the Recycle SMGBF operating modes. Gas velocities up to $6 \mathrm{ft} / \mathrm{s}$ and moving bed velocities ranges identical to the cold model tests are used. The fly ash loading will be at a nominal value of $5000 \mathrm{ppm}$ by weight.

The fly ash collection efficiency will be evaluated by isokinetic sampling of the outlet gas stream. The fly ash loading can be calculated from the fly ash delivered and the gas flow rate. The bed velocity will be calculated from the weight change of the feed bin over the duration of the run. All pressure drop and gas flow will be monitored continuously for further analysis. 


\section{Permissible Ranges of Key Parameters}

The gas velocity operating conditions selected for the testing cover the range of permissible parameters based on economic competitiveness with ceramic barrier filters. Design features can be modified during the testing.

The operating condition ranges will be limited to those outlined below:

\begin{tabular}{|c|c|}
\hline gas environment & - oxidizing \\
\hline Temperature & $-1550^{\circ} \mathrm{F}$ \\
\hline Pressure & $-\quad 10 \mathrm{~atm}$ \\
\hline Gas face velocities & - 3 to $6 \mathrm{ft} / \mathrm{s}$ through the standleg \\
\hline Bed media/fly ash ratio & -5 to 20 \\
\hline Dust loading & - nominally 5000 ppm by weight \\
\hline Bed media material & - to be selected \\
\hline Fly ash material & - $\quad$ PFBC \\
\hline Operating modes & - recycle \\
\hline
\end{tabular}

\section{- Performance Goals}

The performance goals for the HTHP unit testing are:

pressure drop (psi)

particle emission (ppmw)
PFBC

3

20 $\underline{\text { IGCC }}$

6

100

While these goals can be applied directly to the assessment of the HTHP test results, any specific PFBC and IGCC process and application will have a set of performance requirements that may differ from these general criteria.

\section{Test Matrix}

A test matrix will be devised from the results of the cold flow model testing, and will include tests relating to Recycle SMGBF. The test parameters will be limited in number. 


\section{Data to be Collected}

All gas flow, bed media flow, fly ash flow rate, pressure drop across the standleg, and key temperatures will be continuously monitored. The fly ash delivered will be determined through mass balance on loss-in-weight dust feeder. The gas flow will be measured with a turbine flow meter, and the bed media flow determined from the weight change of the bed media feed bin. From those measurements, the fly ash loading, the gas face velocity, the moving bed velocity, and the fly ash collection efficiency can be derived.

Pressure drop across the standleg and the absolute pressure at dirty gas inlet and clean gas outlet will be measured with pressure transducers or gages for further analysis.

Comparison will be made with the HTHP projections made from the cold model test results to identify possible behavior differences and to confirm expectations. 


\section{ESTIMATED COST AND SCHEDULE FOR OPTION 1 TEST PROGRAM}

The materials and test operation labor for this task are estimated below, listing them according to the 3 activities to be performed.

$\begin{array}{clc}\begin{array}{c}\text { Materials } \\ (\$ 1000)\end{array} & \begin{array}{l}\text { Test Labor } \\ (\$ 1000)\end{array} & \begin{array}{c}\text { Total } \\ (\$ 1000)\end{array}\end{array}$

1. Engineering modeling and evaluation:

$\begin{array}{rrr}0 & 45 & 45 \\ 30 & 125 & 155 \\ 35 & 115 & 150\end{array}$

TOTAL

65

285

350

The Option 1 test program schedule is displayed in Figure 11. 
Figure 11 - Option 1 Test Schedule

$$
\begin{array}{ccc}
1994 & 1995 \\
/ \mathrm{J} / \mathrm{A} / \mathrm{S} / \mathrm{O} / \mathrm{N} / \mathrm{D} / \mathrm{J} / \mathrm{F} / \mathrm{M} / \mathrm{A} / \mathrm{M} / .
\end{array}
$$

1. Modeling

and Evaluation

2. Cold Flow Model

Design

Fabrication

Testing

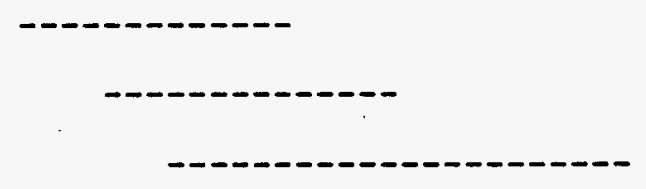

3. HTHP Facility

Design

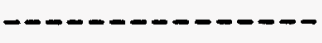

Fabrication

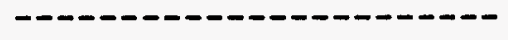

Testing

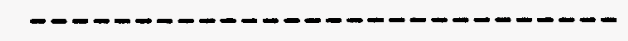




\section{M97002257}

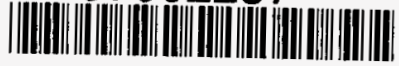

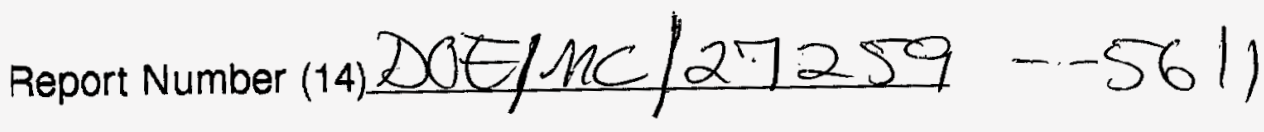

subl. Date (11)

sponsor Code (18)

JC Category (19)

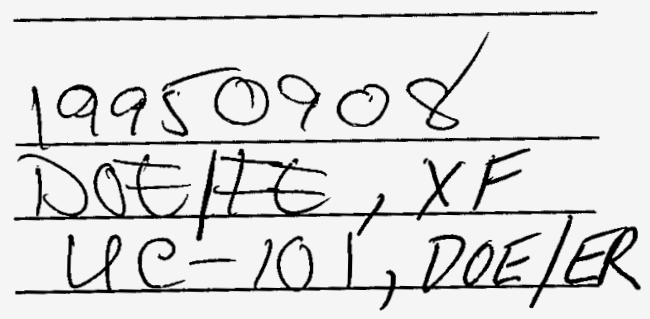

